including tularemia, botulism, and brucellosis.

Antibiotics can be used both before exposure and immediately after exposure to prevent disease caused by sensitive bacteria, but are ineffective against organisms that are naturally or artificially resistant to them. Although using antibiotics for long-term prophylaxis is unrealistic because of the cost, logistic burden, and side effects, good results can be used if they are given shortly after exposure if an attack has been identified. Currently, quinolones such as ciprofloxacin are recommended widely for prophylaxis and therapy of plague and anthrax. There are very few useful antiviral agents, but cidofovir may be useful against smallpox. Generic immunomodulators can have a wide spectrum of activity, but are likely to be of limited utility because of side effects.

Keywords: anthrax; antibiotics; antiviral agents; attack; bacteria; bruccelosis; botulism; cost; immunomodulators; plaque; smallpox; terrorism; tularemia; vaccination; vaccines; viral; warfare, biological

Prehosp Disast Med 2003:18:s(1)s11.

\section{Free Topics}

\section{The International Health Specialist Program}

\section{Lieut. Col. Eugene Bonventre}

United States Air Force

International security challenges have changed significantly in the past decade. The bipolar world no longer exists; threats present themselves from many different sources, often as a result of a clash between different cultures. According to the Chief of Staff of the United States (U.S.) Air Force, "our expeditionary force requires airmen with international insight, foreign language proficiency, and cultural understanding."

The International Health Specialist (IHS) Program was created in 2001 as a cadre of medical professionals who possess language and cultural skills matched to military needs, to facilitate relationships with international civilian and military partners. The IHS personnel establish contacts with the Red Cross Movement and key United Nations agencies. They coordinate their efforts with nongovernmental organizations (NGOs), being careful not to violate the NGO's neutrality. They coordinate U.S. participation in exercises, such as MEDCEUR in the Baltics and Central and Eastern Europe, and MEDFLAG in Africa. The IHS program accepts all medical specialties, but members must maintain currency and competency in their primary medical specialty.

The European IHS team is based at the Ramstein Air Base in Germany. Two recent missions will be discussed. In Uganda, IHS interfaced with UNAIDS and the World Health Organization (WHO) to provide medical care in remote villages, and organized outcome studies to demonstrate their efficacy. In Sierra Leone, the IHS helped to rebuild a medical system ravaged by civil war. Both missions required situation-specific cultural knowledge, training, and experience.

Cultural skills are critical in shaping world events. It is hoped that such "medical diplomats" will facilitate regional cooperation in potential conflict zones.

Keywords: culture; efficacy; exercises; International Health

Specialists; language; non-governmental organizations; Red

Cross; security; U.S. Air Force; war, civil; World Health

Organization

Prebosp Disast Med 2003:18:s(1)s11.

E-mail: eugene.bonventre@ramstein.af.mil

Organization-Methodic Problems of Established

Medical-Diagnostic Standards in Trans-Border

Situations

Prof. Victor N. Preobrazbensky

All-Russian Centre for Disaster Medicine ("Zaschita"), Moscow,

Russia

Russia's experience in emergency health relief, including at the international level (Turkey, Colombia, Afghanistan) shows the necessity of developing international standards to increase efficiency in rendering medical assistance. At the same time, analysis of the existing standards of medical provision at the prehospital stage in some European countries in chemical accidents relief shows the need for detailed consideration and comparison of main indices for the provision of medical evacuation. Thus, it is necessary to analyze the existing approaches to the provision of medical evacuation in trans-border emergencies using the following main trends: (1) principles of medical triage of the injured; (2) amount of medical assistance provided at the prehospital stage; and (3) principles of evacuation of the injured.

The international experience of ARCDM "Zaschita" in health relief following earthquakes shows that it is necessary to unify medical diagnostic tactics in field medical institutions on the diagnosis and treatment of post-traumatic shock, crush syndrome, etc., to form a complex of medical-preventive measures during evacuation of the injured with the given pathology, etc. Thus, for the provision of medical evacuation in emergency trans-border relief, it is necessary to form a working group with representatives from different countries to analyze existing experience and establish unified standards.

Keywords: aid; ARCDM; assistance; chemical events; diagnosis; earthquakes; evacuation; experience; organization; prevention; relief; standards; trans-border; triage; "Zaschita"

Prehosp Disast Med 2003:18:s(1)s11.

E-mail: rcdm.org@ru.net

\section{Emergency Medical Care in Mass Trauma and Methodology for Its Realization \\ Dr. George OrakhelashviIi}

Tbilisi State Medical University, Tbilisi, Georgia

Forecasting and prevention of catastrophic events and elimination of their consequences have become one of the major problems in the world. One of the most devastating events, the place and time of which is practically impossible to forecast, is an earthquake. However, the practice of organizing emergency medical care for the victims of an earthquake indicates that such care, as a rule, is improvised, delayed, and inefficient. Thus, the development of new complex strategies for organizing and improving intra- and inter-state systems for emergency medical care during disasters is essential.

Therefore, in the Department of Disaster Medicine, a 